84. Frenkel' S. Ya. (1973) Polimeryi. Problemyi, perspektivyi i prognozyi. Fizika segodnya i zavtra: za redaktsiieiu V. M.Tuchkevicha. Leningrad: Nauka. Ss.176-270.

85. Feynman R. P. (1966) The Development of the Space-Time View of Quantum Electrodynamics. Science. Vol. 153, No. 3737. Pp. 699-708.

86. Pogrebnyak V.G., Perkun I. V., Pogrebnyak A. V. (2016)Displacement of Oil from Porous Bed by the Oscillating Flow of Polymer Solution. American Journal of Science. Engineering and Technology. Vol. 1, No 2. Pp. 53-57.

https://doi.org/10.31713/m1107

\title{
TECHNOLOGY OF RAW MATERIAL ENRICHMENT OF INHOMOGENEOUS CARBONATE DEPOSITS AND EVALUATION OF ITS ENERGY EFFICIENCY
}

\section{Dreshpak O. S.}

Dnipro University of Technology, $\mathrm{PhD}$, associate professor, Department of Technological Engineering of Materials Processing, Ukraine

\section{Dreshpak N. S.}

Dnipro University of Technology, $\mathrm{PhD}$, associate professor, Department of Electrical Engineering, Ukraine

\section{Vypanasenko S. I.}

Dnipro University of Technology, DSc (Engineering), professor, Department of Power Engineering, Ukraine

\begin{abstract}
The article presents the results of solving the urgent scientific and practical problem of establishing regularities connecting the indicators of the efficiency of enrichment and classification of raw materials of heterogeneous limestone deposits with its initial characteristics, technological and design parameters of the classification equipment, substantiating rational screening modes on this basis. An assessment of the energy efficiency of the proposed technical solutions is given. The research was carried out at Dnipro University of Technology (Ukraine, Dnipro).

Technological lines for dry processing of limestone raw materials, which are used in quarries, ensure the production of marketable products of acceptable quality only for large grades of crushed stone in low humidity conditions. Small grades of crushed stone are not used and are sent to the dump. There is a need to improve the existing process of classification and enrichment of raw materials in order to improve the quality of the final product and expand, on this basis, the fractional com-
\end{abstract}


position of commercial crushed stone, which complies with the requirements of state standards.

The proposed concept of enrichment of raw materials of heterogeneous carbonate deposits consists in the forced separation of clay coatings from pieces of rock, followed by highly efficient screening of limestone in quarry conditions. The implementation of the concept provides for the use of a roller-finger screen, which provides high performance indicators at high material moisture. New analytical dependencies have been obtained linking the indicators of the efficiency of limestone concentration with the results of the granulometric and chemical analyses of the feedstock, the efficiency of its screening. On their basis, a mathematical model has been created that allows, with a limited amount of experimental data, to predict the achieved enrichment efficiency indicators, taking into account the characteristics of the classification devices used.

It is shown that the dependence of the indicator of the efficiency of enrichment of raw materials on the size of the separation of particles by screening devices has an extremum, and the value of the size corresponding to the maximum of the indicator does not depend on the efficiency of screening. This makes it possible to use a screening mode with an optimal particle size separation, while ensuring high enrichment efficiency, reducing waste from the processing process, and improving the ecological situation in the region.

A method for calculating the optimal size of the separation of the material to be classified has been developed. On its basis, an algorithm for calculating the indicators of the concentration efficiency was created, which allows obtaining expanded information on the nature of changes in certain parameters with a variation in the size of the separation of particles and screening efficiency.

The use of a roller-finger screen as a combined device, which carries out both the separation of clay coatings from pieces of limestone, and the separation of particles by size (including conditions of high humidity of the feedstock), improves the screening efficiency. Based on the study of the dynamics of the particle of the material, the determination of the forces acting on the particle, the obtained analytical dependence determines the condition for excluding the mode of its infringement. It is proved that such a regime does not depend on the levels of forces acting on the particle, but is determined exclusively by the values of the angles characterizing the position of the points of contact of the particle with parts of adjacent rolls.

To study the enrichment and classification processes of the feedstock, linear regression multifactor models were created, where the values of the limestone content in the feedstock and the moisture content of the material were used as factors, and the values of the indicators of the efficiency of enrichment and screening of limestone were used as the response functions. The models allow the comparing of the efficiency of screening and beneficiation processes in classification options with and without a roller-finger screen.

The presence of a roller-finger screen is manifested in its stabilizing effect on the classification process, which is accompanied by an increase in the beneficiation efficiency by $10-20 \%$.

Along with the tasks of increasing the efficiency of enrichment of raw materials from carbonate deposits, the indicators of the energy efficiency of the technological 
process are considered. A methodology for assessing the energy intensity of the existing and proposed raw material enrichment technology has been developed. The structure of the regression model for standardizing the indicator of specific electricity consumption is proposed and a list of measures that are advisable to use in order to improve energy efficiency is determined.

Key words: enrichment efficiency, raw material classification, finger-feller screen, limestone, raw material moisture.

\section{Introduction}

The metallurgical and construction industries are the main consumers of limestone. Requirements for commercial limestones are set out in regulations and are sufficiently meaningful and complex to implement. The content of clay particles in the commodity product is normalized. In different classes of carbonate rocks, the maximum allowable values of clay additives are different, but should not exceed $20 \%$. Upper calcite levels in standard size classes are not limited. In the process of enrichment of raw lime deposits, it is important not to reach the lower limit of calcite content. The presence of clay particles in the form of films, and primers significantly worsens the conditions for obtaining a high quality product. Grinding and grading operations are used to process raw materials. The low efficiency of the classification process is the reason for the continuous growth of tailings. There is a need to improve the existing technological lines of enrichment of raw materials in order to improve the quality of the product, expanding its fractional composition. In conditions of high humidity of raw materials clay additives create problems with the classification of limestone. Increasing the moisture content of the raw material to be sieved leads to clumping of the clay during processing, its adhesion to the surface of the sieves, which reduces the efficiency of classification, and in some cases the process can not be implemented. At the same time, the company incurs significant losses associated with reduced production.

Outstanding scientists of Ukraine and abroad havedealt with scientific problems of dry classification of raw materials: Andreev S.E., Bardovsky A.D., Berdus V.V., Blekhman I.I., Weisberg L.A., Kartaviy N.G., Levendell E. E., Levenson L.B., Liandov K.K., Inflated V.P., Nepomnyashchy E.A., Olevsky V.A., Olyunin V.V., Pilov P.I., Poturaev V.N. ., Rundqvist K.A., Teacher A.D., Franchuk V.P., Chervonenko A.G., Shlain B.I. and others. Wet processing of 
inhomogeneous carbonate rocks in the quarry is practically impossible, as in most cases there is no ability to provide the process with water in the required amounts; it is not possible to dispose of production sludge. Dry methods of processing raw materials, accompanied by the separation of its clay particles, are not effective enough and need improvement. In the conditions of dry processing of raw materials it is necessary to focus on the expanded operational modes characterized by high indicators of efficiency of screening, in the direction of increase of values of humidity of material acceptable for this process. This will reduce the dependence of equipment modes on weather and seasonal conditions, and reduce interruptions in the operation of production lines.

It is shown that theoretical research in the field of enrichment and classification of materials focuses mainly on establishing the links between known indicators of enrichment efficiency, classification of raw materials and technological, design parameters of the equipment that performs these processes. Methods of probability theory and mathematical statistics are widely used.

Recently, much attention has been paid to ensuring high energy efficiency of mineral beneficiation processes. Such processes are usually energy intensive. Indicators of specific energy consumption are units, and often tens of $\mathrm{kW} \cdot \mathrm{g} / \mathrm{ton}$. With significant volumes of raw material processing, energy costs are significant, which determines the relevance of research aimed at improving energy efficiency of processes. The application of operating regimes with high efficiency of screening of limestone raw materials should be accompanied by an assessment of energy efficiency of decisions taken before implementation. It is expedient to compare the energy efficiency indicators of the existing and the proposed enrichment technologies. The indicator of energy efficiency largely depends on the control of its importance in the process of enrichment of raw materials and the timely application of measures to improve it. To carry out such control, it is necessary to determine the normalized values of energy consumption, which fully meets the requirements of the current standard ISO50001.

\section{Research methods and results}

The problem is one of determining the relationship between the efficiency of enrichment of limestone raw materials with the results 
of its particle size and chemical analysis and the efficiency of classification. On this basis, a mathematical model for forecasting this indicator was developed, rational screening regimes were substantiated, and a method for calculating indicators of the enrichment process was created. The accepted concept of limestone enrichment of inhomogeneous deposits is determined. It is shown that with increasing the size of raw materials, the content of calcite increases, and clay additives - decreases. At the same time, the results of the analysis show that even large classes do not contain enough limestone to classify them as a marketable product. Uneven distribution of calcite content in different size classes is a prerequisite for solving the problem of limestone enrichment by classifying the raw materials of the deposit. But obtaining a marketable product only by classifying raw materials is not always possible (for example, in the absence of sufficient calcite in large fractions). It is known that the increase in moisture content of raw materials is accompanied by a decrease in the efficiency of screening and even a possible shutdown of the production line. Therefore, in the technological line of raw material processing it is necessary to introduce an additional element that eliminates the negative consequences. The heterogeneity of raw materials of carbonate deposits introduces uncertainty into the results of its enrichment with existing technological lines. Therefore, it is important to predict the efficiency of enrichment, the quality of the obtained product, based on chemical and particle size analysis of raw materials for a particular field, and the modes of operation of technological equipment. It should be noted that the existing technologies of enrichment of raw materials and the proposed concept of enrichment provide for the implementation of the final classification operation, which determines the achieved level of enrichment. Therefore, the paper focuses on creating a mathematical model for predicting the efficiency of enrichment by classifying raw materials. The acceptability of the use of power functions in regression dependencies reflecting the results of chemical and granulometric analysis of raw materials of inhomogeneous carbonate deposits is confirmed.

$$
m_{2 d} / m=a_{1} d^{n_{1}}+b_{1} ; m_{u 2 d} / m=a_{2} d^{n_{2}}+b_{2},
$$

where $m_{2 d}$ - the mass of the particles of the lower size class in the product to be classified; $m_{u 2 d}$ - mass of limestone in the lower size 
classes of this product; $m$ - the mass of the product; $a_{1}, a_{2}, b_{1}, b_{2}, n_{1}$, $n_{2}$ - coefficients of degree regression dependence (for raw materials of Zapadno-Tyaginsky deposit $a_{1}=22,403 ; a_{2}=7,962 ; b_{1}=-0,675 ; b_{2}=-$ 0,$\left.271 ; n_{1}=0,347 ; n_{2}=0,448\right) ; \mathrm{d}$ is the size of the separation of raw material particles in the screening process.

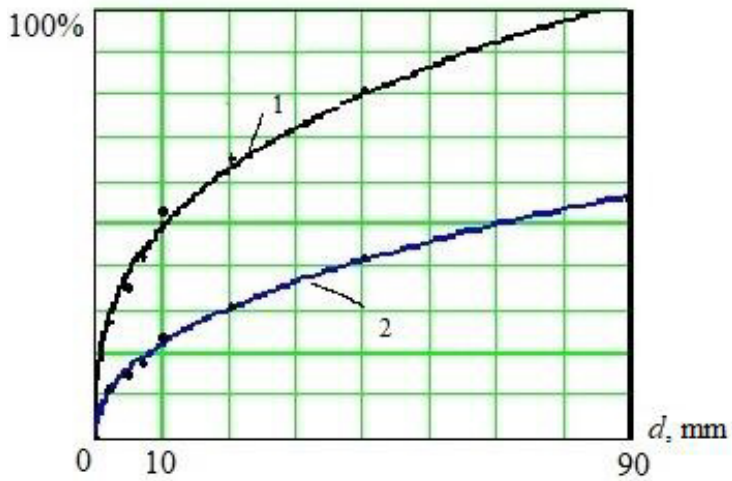

Fig. 1. Dependences between output $m_{2 d} / m(d)=\gamma$ and $m_{u 2 d} / m(d)=\alpha$ limestone content in the total sample $\left(m_{2 d} / m(d)\right.$ - curve 1 and $m_{u 2 d} d m(d)$ - curve 2)

The calculated values of the correlation relations $r$ for the considered models were: for curve $1-r=0,997$, curve $2-r=0,998$. The experimental points shown in Fig. 1 practically coincide with curves 1 and 2. High levels of correlation relations allow us to consider the dependences (1) with appropriate assumptions that reflect the functional relationships between parameters and use them in the developed model, to calculate the determined values of enrichment efficiency indicators.

Taking into account the dependence $m_{2 d}(d)$ we obtain

$$
\frac{m_{1 d}}{m}(d)=1-\frac{m_{2 d}}{m}(d),
$$

where $m_{1 d}$ - the mass of particles of the upper size class in the product to be classified.

Mass of oversized product $m_{1}$ :

$$
m_{1}=m_{1 d}+m_{2 d}\left(1-E_{s}\right)
$$

where $E_{s}=m_{2 /} m_{2 d}\left(E_{s}-\right.$ screening efficiency); $m_{2}-$ the mass of the sub-sieve product.

Output of over sieve $\left(\gamma_{1}\right)$ and sub-sieve $\left(\gamma_{2}\right)$ products 


$$
\gamma_{1}=\frac{m_{1 d}}{m}+\frac{m_{2 d}}{m}\left(1-E_{s}\right) ; \quad \gamma_{2}=1-\gamma_{1}
$$

The use in equations (3), (4) of the variable $E_{s}$, which can vary within $0 \leq E_{s} \leq 1$ depending on the achieved level of screening efficiency, allows in the following analysis to consider the dependence of parameters characterizing the enrichment process, not only on the variable $d$, but also from the value of $E_{s}$.

The content of limestone in the over sieve $\left(\beta_{1}\right)$ and sub-sieve $\left(\beta_{2}\right)$ products is calculated by the formulas

$$
\begin{gathered}
\beta_{1}=\frac{m_{u 1}}{m_{1}}=\frac{m_{u 1 d}+m_{u 2 d}\left(1-E_{s}\right)}{m_{1 d}+m_{2 d}\left(1-E_{s}\right)}=\frac{\frac{m_{u 1 d}}{m}+\left(\alpha-\frac{m_{u 1 d}}{m}\right)\left(1-E_{s}\right)}{\gamma_{1}}, \\
\beta_{2}=\frac{m_{u 2}}{m_{2}}=\frac{\alpha-\left(\frac{m_{u 1 d}}{m}+\left(\alpha-\frac{m_{u 1 d}}{m}\right)\left(1-E_{s}\right)\right)}{1-\gamma_{1}}
\end{gathered}
$$

where $m_{u 1}, m_{u 2}$, - the mass of limestone in the super-lattice and sub-lattice products; $\alpha$ - lime content in the product to be sieved; $m_{u l d}$-the mass of limestone in the upper grades of the size of the product to be sieved.

Equations (4), (5) allow determining the indicators of limestone extraction in superscreen $(\varepsilon 1)$ and subsieving $\left(\varepsilon_{2}\right)$ products.

In addition to the enrichment index $E$, the model allows to calculate the values of parameters $\gamma_{1}, \gamma_{2}, \beta_{1}, \beta_{2}, \varepsilon_{1}, \varepsilon_{2}$ which are also important characteristics of the process.

We use a mathematical model to predict the efficiency of limestone beneficiation of the Zapadno-Tyaginsky deposit and consider the dependence $E\left(E_{s}, d\right)$ obtained by calculation, where models (1) are used. The family of characteristics $E(d)$ at different values of $E_{s}$ illustrates Fig.2. The analysis shows that the increase in $E_{s}$ is accompanied by an increase in E. These curves have extremes. The maximum values of $E$ for different curves $(1,2,3)$ correspond to the same values of the size $d$ (about $7 \mathrm{~mm}$ ). Assuming the value of $d=7 \mathrm{~mm}$ as a rational value of the size of the separation of raw materials $\left(d_{o p t}\right)$, we conclude that $d_{\text {opt }}$ does not depend on $E_{s}$, i.e. for arbitrary values of $E_{s}$ at $d=d_{\text {onm }}$ the maximum level of enrichment is provided. The use of this mode is important for the practical implementation of the screening device, as the size of the sieve gaps should be set equal to $d_{\text {opt }}$. 
Calculations show that the nature of the dependences $E(d)$ shown in Fig. 2 is preserved at different values of the limestone content in the raw material $\alpha$. Variation $\alpha$ leads only to a change in the value of $d_{\text {opt }}$, which provides the extremes of the family of functions. The second important conclusion, which follows from Fig. 2, is that even effective screening modes $\left(E_{s}=0,9-\right.$ $1,0)$ are not able to provide high rates of enrichment efficiency (maximum value of $\left.E_{s}=0,2\right)$. Therefore, the raw materials of the Zapadno-Tyaginsky deposit need additional processing, for example, within the framework of the concept of enrichment proposed by the authors.

The practical use of the developed model to predict the effectiveness of enrichment involves the implementation of a certain sequence of actions. This sequence is presented in the form of a method of calculating the rational value $d_{\text {opt }}$. The following sequence of actions is defined:

1. Perform particle size and chemical analysis of raw materials to be classified.

2. Get the regression dependences $m_{2 d} / m(d), m_{u 2 d} / m(d)$.

3 . Construct the dependence $E(d)$ and find the value $d_{o n m}$ corresponding to the maximum level $E$.

4. For the mode of operation of the screen $d=d_{\text {opt }}$ to determine the corresponding indicators $\gamma_{1}, \gamma_{2}, \beta_{1}, \beta_{2}, \varepsilon_{1}, \varepsilon_{2}$.

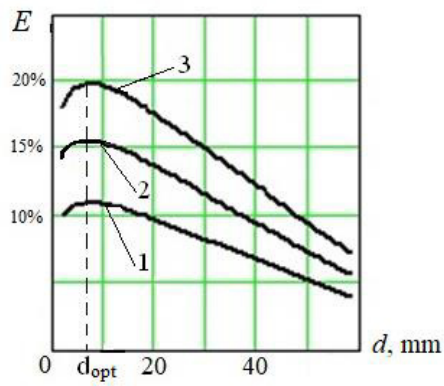

Fig. 2. Dependence between enrichment efficiency $E$ and separation size $d$ at different values of screening efficiency $E_{s}$ (curve $1-0,7$; curve 2-0,8; curve $3-0,9$ )

To simplify the procedure of using the proposed technique developed an algorithm for calculating the indicators listed in paragraphs $2,3,4$. The algorithm is implemented in MathCAD and allows to obtain advanced information about the nature of changes in the calculated parameters for variations $d$ and $E_{s}$. 
To determine the parameters of power dependences (1) it is possible to use the method of interpolation of the function, which will allow in the conditions of rapid analysis to abandon a series of experiments (to build a regression dependence) and limit their number to two. This is important to reduce the amount of work, as well as the time required to perform calculations. The accuracy of the forecast when using the proposed model depends on the values of correlation relations in equations (1). This allows the researcher to independently assess the accuracy of the calculation results and decide on its acceptability. To assess the reliability of the calculation results, a comparison of the calculated and experimental data obtained in the laboratory was performed. The discrepancy between these data did not exceed $7 \%$.

The universality of the developed technique is that it uses the developed mathematical model and can be used to analyze the raw materials of any inhomogeneous carbonate deposit. The practical significance of the proposed method is that it allows to determine the optimal screening regimes, to assess the levels of enrichment efficiency that can be achieved by classifying raw materials.

The use of traditional sieves with sieving surfaces for the classification of raw materials does not ensure the stability of the enrichment results as a result of the adhesion of fine particles of raw materials at high humidity. Based on this, in the practice of screening, the process is transferred to the mode of operation of the screen, where the adhesion of particles is manifested to a small extent. Practical experience in the processing of raw materials shows that this mode is characteristic of the particle size separation $d \geq 20 \mathrm{~mm}$. In the practice of classification of raw materials to increase the efficiency of enrichment E usually implement the lower limit $(d=20 \mathrm{~mm})$. The analysis shows that significant volumes of processed raw materials with a high content of limestone end up in the dump. Accumulation of material in the tailings leads to environmental problems.

In the current situation, it is advisable to change the mode of operation of the screen in such a way as to achieve the maximum value of limestone extraction (Fig. 2). It is necessary to ensure in the mode $d=d_{\text {opt }}$ high screening efficiency $E_{s}$. In conditions of high humidity of raw materials such efficiency is provided by roller screens where openings are continuously cleared of sticking. Increasing humidity helps to reduce the strength 
of clay coatings. There are favorable conditions for their separation by applying to the surfaces of solid parts of raw materials little effort, which is achieved by the use of roll-finger screens.

To exclude the possibility of limestone clamping modes, it is necessary to study the dynamics of material particles. The forces acting on the spherical particle are determined (Fig. 3) and the analytical dependence is obtained, which determines the condition of excluding the mode of its clamping

$$
\frac{\cos \beta \cdot \sin \frac{\alpha}{2}+\cos \gamma \cdot \sin \frac{\alpha}{2}-\cos \left[\beta-\left(\frac{\pi}{2}-\frac{\alpha}{2}\right)\right]}{\cos \beta \cdot \cos \frac{\alpha}{2}-\cos \gamma \cdot \cos \frac{\alpha}{2}}>f,
$$

It is shown that this mode does not the grip angle $\alpha$ and the angle $\beta$, which characterizes the position of the point of contact of the particle material to the finger. The analysis of the functional dependence shows that when the angle $\beta$ increases, the range of acceptable (in terms of eliminating the clamping of particles) values of $\alpha$ is shifted to the zone of decrease in the numerical values of the angle $\alpha$. Changing the coefficient of friction to a small extent does not lead to a significant change in the areas corresponding to the mode of ejection of particles from the danger zone. Determining the functional dependence allows the designers of the screens to check the design to exclude the mode of clamping particles.

In determining the design parameters of the screen, it is advisable to implement the division at the level of $d=d_{\text {opt }}$. It is shown that in the design of a disk with two fingers it is rational to provide the height of the finger $h=d_{\text {opt }}$. In the four-finger design, the size of the hole, which provides a given size of the separation of particles $d$, exceeds the same size in the two-finger design. The value of this excess depends on the design parameters of the disk and should be taken into account when designing screens.

Let's estimate efficiency of use of a screen of a new design in the conditions of change of humidity of initial raw materials. For this purpose, regression mathematical models have been developed to calculate the efficiency of enrichment and classification of the material. 


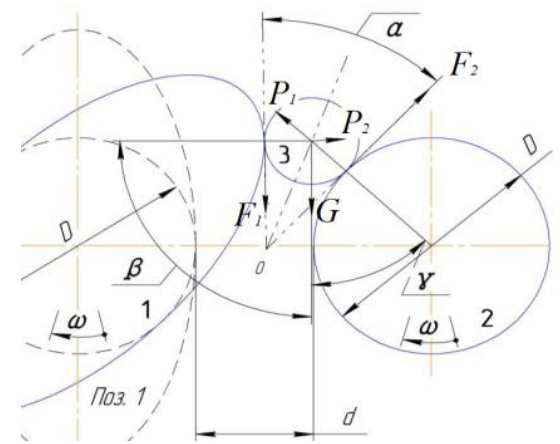

Fig.3. Forces acting on a particle of material

The difficulty of determining the functional relationships between variables that reflect the effectiveness of the processes of classification and enrichment, as well as the parameters that determine them, is the multifactorial nature of the problem, the complexity of the mathematical description of dependencies. Therefore, it is advisable to investigate stochastic relationships between variables, in particular to use regression analysis.

The hypothesis of the adequacy of nonlinear one-factor models is confirmed (1). To do this, the variance of adequacy $S_{a d}^{2}$, the variance of reproducibility of the experiment in parallel experiments $S_{r e p}^{2}$ is determined. The homogeneity of the variances in the experiments was confirmed by applying the Cochren test. The calculated $F_{\mathrm{p}}$ and tabular $F_{\mathrm{t}}$ values of the Fisher test are compared.

To confirm the feasibility of using roller-finger screen in the technological line of raw material beneficiation, it is necessary to create mathematical models to calculate the efficiency of beneficiation $E$ and screening $E_{s}$ in the presence and absence of such screen in the technological line. The formation of models takes into account factors that change significantly in the conditions of production, such as: limestone content $\alpha$ (factor $X_{1}$ ) and moisture $W$ of raw materials (factor $X_{2}$ ). The limits of change of factors $X_{1}$ and $X_{2}$ are determined.

Other factors influencing the values of $E, E_{s}$, in the conditions of experiments remained unchanged. Thus, four regression models have been developed 


$$
\begin{array}{ll}
\hat{Y}_{E C}=b_{03}+b_{11} X_{1}+b_{21} X_{2}, & \hat{Y}_{E S C}=b_{03}+b_{13} X_{1}+b_{23} X_{2} \\
\hat{Y}_{E H}=b_{02}+b_{12} X_{1}+b_{22} X_{2}, & \hat{Y}_{E S H}=b_{04}+b_{14} X_{1}+b_{24} X_{2} .
\end{array},
$$

Here $\hat{Y}_{E C}, \hat{Y}_{E H}, \hat{Y}_{E S C}, \hat{Y}_{E S H}$ - estimates of mathematical expectations of parameters: $\hat{Y}_{E C}$ - parameter $E$ without the use of roller-finger screen; $\hat{Y}_{E H}$ - parameter $E$ in terms of its use; $\hat{Y}_{E S C}$ - parameter $E_{s}$ in the absence of a screen; $\hat{Y}_{E S H}$ - parameter $E_{s}$ in its presence; $b_{i j}$ - regression coefficients.

The matrix method of calculating the coefficients of regression dependences is used. To assess the adequacy of multifactor models (7), the values of adequacy variances $S_{a d}^{2}$ and reproducibility variances $S_{\text {rep }}^{2}$ were determined, and the homogeneity of variances in the experiments was confirmed. The significance of the coefficients $b_{i j}$ in the regression equations (7) is estimated. The application of Fisher's criterion confirmed the adequacy of the developed models.

A factorial experiment of type $\left\langle 2^{2} »\right.$ was performed. Using orthogonal planning, an experimental plan is drawn up.

Table 1

Experiment plan

\begin{tabular}{c|c|c|c|c|c|c|c}
\hline $\begin{array}{c}\text { № } \\
\text { eperiment }\end{array}$ & $X_{0}^{*}$ & $X_{1}^{*}$ & $X_{2}^{*}$ & $\hat{Y}_{E C}$ & $\hat{Y}_{E H}$ & $\hat{Y}_{E S C}$ & $\hat{Y}_{E S H}$ \\
\hline 1 & + & - & - & $Y_{E C 1}$ & $Y_{E H 1}$ & $\hat{Y}_{E S C 1}$ & $\hat{Y}_{E S H 1}$ \\
\hline 2 & + & + & - & $Y_{E C 2}$ & $Y_{E H 2}$ & $\hat{Y}_{E S C 2}$ & $\hat{Y}_{E S H 2}$ \\
\hline 3 & + & - & + & $Y_{E C 3}$ & $Y_{E H 3}$ & $\hat{Y}_{E S C 3}$ & $\hat{Y}_{E S H 3}$ \\
\hline 4 & + & + & + & $Y_{E C 4}$ & $Y_{E H 4}$ & $\hat{Y}_{E S C 4}$ & $\hat{Y}_{E S H 4}$ \\
\hline
\end{tabular}

Modeling of the process of raw material enrichment using dependences (7) shows that $1 \%$ change in moisture content of raw material $W$ leads to a greater change in $E, E_{s}$, than $1 \%$ change in limestone content in raw materials, i.e. the degree of influence of model factors on function feedback is different. The screening efficiency of the parameter $E_{s}$ depends to a small extent on the limestone content $\alpha$. There is a significant dependence of the parameter $E_{s}$ on the mois- 
ture content of raw materials. At increase of humidity of raw materials to $12 \%$ efficiency of parameter $E_{s}$ with use of a roller-finger screen exceeds the existing indicator in 2 times that promotes stabilization of value of this indicator in the course of change of humidity of raw materials (Fig. 4). The increase in the parameter $E_{s}$ is accompanied by an increase in the efficiency of enrichment of the parameter $E$ by $10-20 \%$ (compared to the option without a screen).
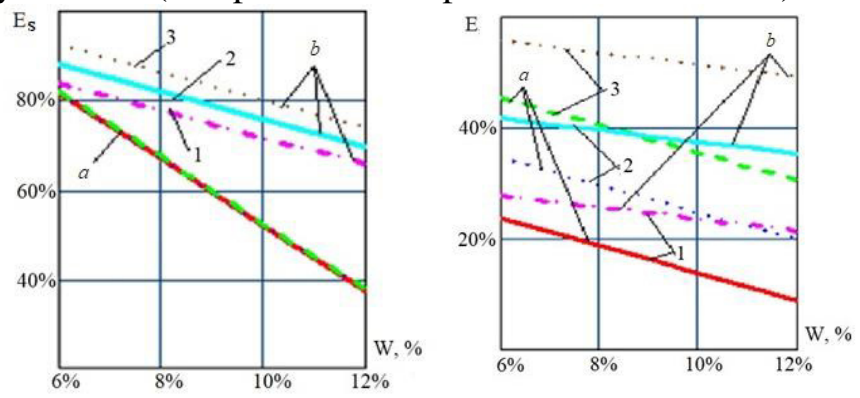

Fig.4. Dependence between screening efficiency $E_{s}$ and enrichment $E$ on limestone content $\alpha$ and humidity $W$ ( $a$-without roll-finger screen; $b$-with screen; $1-\alpha=51 \% ; 2-\alpha=65 \% ; 3-\alpha=79 \%)$

The above confirms the feasibility of using roller-finger screens in the technological lines of enrichment of raw materials of heterogeneous carbonate deposits. The experimental sample developed in laboratory conditions finger screen (Fig. 5) implements the results of theoretical studies performed in terms of its design, modes of operation of screens of this type.

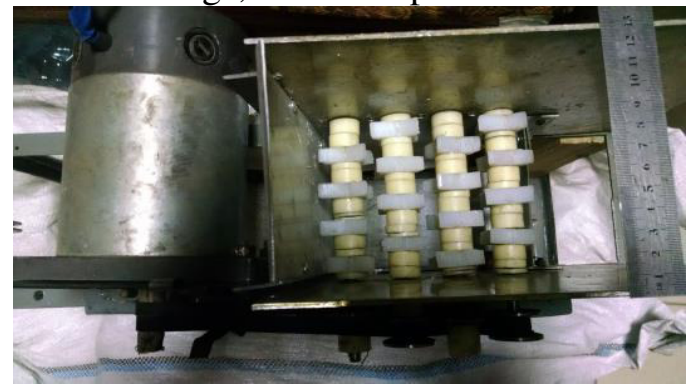

Fig.5. Photo of an experimental sample of the screen

The procedure of sampling for granulometric and chemical analyzes of raw materials is revealed. The results of particle size analysis indicate that the weights of large classes in the raw material are predominant. Chemical analysis confirms the increase in the mass of 
related elements in small size classes. A number of experimental studies were conducted in accordance with the above methods of experiment planning.

During their implementation, the values of the limestone content in the original product and the moisture content of the sample material varied. Modes of classification of materials both with the use of roller-finger screen and without its use were studied. Execution of granulometric and chemical analyzes of sieve and sub-sieve products allowed to determine the achieved indicators of screening and enrichment efficiency, to build on this basis multifactor regression models (7), to perform a comparative analysis of the considered approaches to raw material enrichment (Fig. 4).

The results of the experiments indicate that when using a rollerfinger screen there is an increase in the mass of the sub-sieve product. The mass of clay additives and small particles of limestone increases, and in the case of high humidity (12\%) of the original product, this increase is more noticeable (1.5-2 times), which indicates the feasibility of using roll-finger screens in technological lines of enrichment. It is proposed at the early stage of the process of processing limestone raw materials to classify the material with a rollerfinger screen, ensuring the separation of alumina small particles from larger ones with high limestone content (Fig. 6).

This will allow at an early stage of the processing process to increase the degree of purification of raw materials, improve the working conditions of commercial screens due to the absence of small alumina particles, improve the quality of the resulting gravel. The constructive decisions of rolls and disks of a roll-finger screen are offered and protected by patents. The solution is to place the fingers of the disk relative to the adjacent screen of the screen, using the original mounting fingers on the disk. They ensure the efficiency of the screen, reduce the time of repair work.

Let us turn to the analysis of the efficiency of electricity use by the technological line shown in Fig.6. 


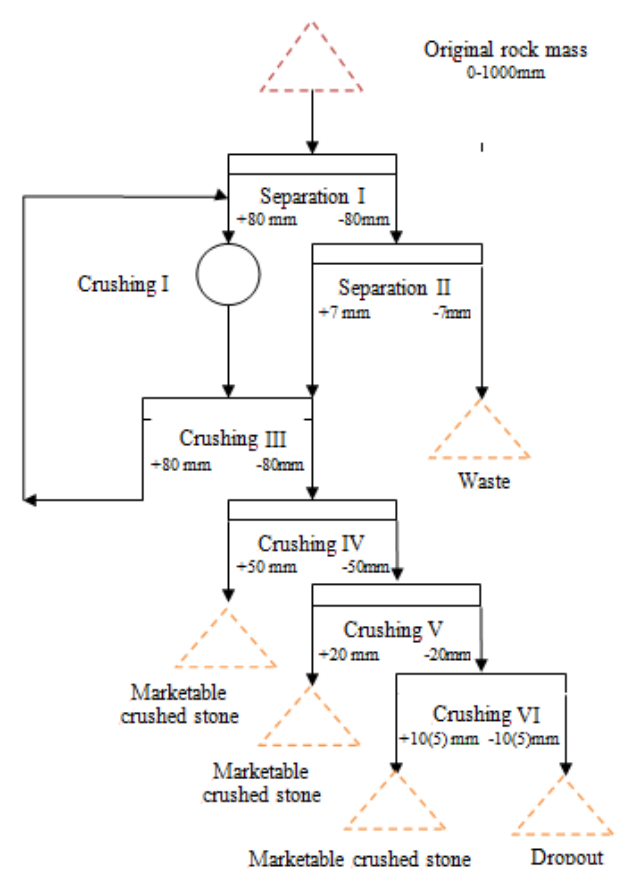

Fig.6. Technological scheme of enrichment with the use of roller-finger screen (separation II)

This scheme of enrichment involves the use in the traditional line of enrichment of an additional element (roll-finger screen). The change in the electrical load of the power supply network of the technological complex is due to the presence of this additional element. The ratio of the average values of power $\left(P^{*}\right)$ of electricity consumed by technological lines with an additional element $\left(P_{\text {add }}\right)$ and without it $\left(P_{\mathrm{abs}}\right)$, determines the quantitative characteristics of such a change. It should be noted that the value of $P^{*}=P_{\text {add }} / P_{\text {abs }}$ can be both smaller and larger than one. It depends on the characteristics of the electrical equipment used. It should also be borne in mind that the presence of a roller-finger screen changes the modes of operation of other elements of the system, reducing the weight of the material to be classified with the release of the product. The energy intensity of the enrichment process must take into account the duration of processing of raw materials. As can be seen from Fig. 4, at the same values of limestone content and its humidity, the value of $E_{s}$ in the 
presence of an additional element $E_{\text {s.add }}$ exceeds the value corresponding to its absence $\left(E_{s . a b s}\right)$. That is, in the presence of a rollerfinger screen, the set value of $E_{s}$ is reached in a shorter period of time. We will assume that the degree of reduction of the time of the classification process is determined by the ratio $T^{*}=E_{s . a b s} / E_{s . a d d}$, which is less than one. Then the relative value of the energy intensity of the process $V^{*}$ (the ratio of energy consumption in the presence and absence of roll-finger screen) is obtained from the dependence

$$
V^{*}=P^{*} \cdot T^{*}
$$

Determination of $V^{*}$ allows to make an approximate assessment of the effectiveness of the introduction of new technology for processing raw materials in terms of its energy efficiency. If the value of $V^{*}$ exceeds one, then the application of new technology requires an increase in energy consumption. If the value of $V^{*}$ is less than one, you should expect a reduction in costs. The proposed method takes into account structural changes in the technological line of enrichment. The implementation of new technology, which involves the use of roller-finger screen, will provide a sustainable change in energy efficiency of the enrichment process. However, there are other components that significantly affect the value of energy intensity of the technological process. Influential factors include the peculiarities of the management of the classification process. Important actions of service personnel (primarily grinding, screening operators) in the process of managing the production line. Usually the control is reduced to the choice of the degree of loading of the line, determining the moments of switching on and off the equipment, the procedure for technological stops. Management should be such as to ensure high efficiency of raw material enrichment with minimum values of specific energy consumption. To do this, operators must reduce the duration of idling modes of the production line, eliminate overload modes, reduce the duration of technological stops. The degree of fulfillment of these requirements depends on the qualifications of service personnel, their motivation to implement the formulated actions. The expediency of introducing control actions to determine the effectiveness of management is obvious.

The task of controlling energy efficiency is not new. The control is carried out by comparing the actual indicators of specific energy 
consumption with the planned ones. Existing differences are subject to analysis and on their basis form actions for process management. There are a number of methods for normalizing the indicators of specific energy consumption. In the conditions of transient changes in the values of specific energy consumption, which is characteristic of the technology of enrichment of limestone raw materials with the implementation of the function of manual process control, it is advisable to use the statistical method of rationing. This method provides sufficient accuracy of the forecast, which allows you to assess the effectiveness of control actions of process operators in a short period of time (per shift, per day). Operational control involves measuring the values of electricity consumed per shift (or day), moisture content of raw materials to be processed, as well as the mass of the resulting product. The values of these parameters, obtained in a volume sufficient for statistical evaluation, are used to construct a regression dependence that determines the planned indicators of energy consumption. It should be noted that the measurement of these parameters with sufficient accuracy is not a time-consuming process and is carried out when collecting statistical information.

It is proposed to use regression dependence to estimate the amount of energy consumed during the change or day of $E_{n}$.

$$
E_{n}=A_{1}+A_{2}(W \cdot N),
$$

where $A_{1}, A_{2}$ - coefficients of regression dependence, $N$ - mass of the product obtained in a given period of time.

The product of $W \cdot N$ takes into account the interaction of two factors influencing (raw material moisture and product weight) on the value of energy consumed. From (9) it is easy to obtain a predicted estimate of the value of specific energy consumption $E_{n}^{*}=E_{n} / N$. In the process of collecting statistical information, it is important to ensure the synchronicity of measuring the values of the dependence parameters (9). Control of energy efficiency allows to assess the contribution of service personnel of the technological complex in the implementation of energy saving tasks. 


\section{Conclusions}

The main scientific and practical results of the work are as follows:

1. Technological lines of dry processing of raw limestone, which are used in quarries, ensure the receipt of marketable products of acceptable quality only for large classes of gravel in conditions of low humidity. Small classes of crushed stone are not used and are sent to the dump. There is a need to improve the existing process of classification and enrichment of raw materials in order to improve the quality of the final product and expand on this basis the fractional composition of commercial gravel that meets the requirements of state standards.

2. The concept of enrichment of raw materials of heterogeneous carbonate deposits is defined, which consists in separation of clay coverings from pieces of rock with the subsequent highly effective screening of a product in quarry conditions. Implementation of the concept involves the use of roller-finger screen, which provides high efficiency at high humidity.

3. New analytical dependences are obtained, which connect the indicators of limestone beneficiation efficiency with the results of granulometric and chemical analyses of raw materials, and the efficiency of its screening. Based on these, a mathematical model was created that allows, with a limited amount of experimental data, the prediction of the achieved indicators of enrichment efficiency, taking into account the characteristics of the applied classification devices.

4. It is shown that the dependence of the raw material enrichment efficiency indicator on the particle size separation by screening devices has an extremum, and the size value corresponding to the maximum of the indicator does not depend on the screening efficiency. This allows you to use the screening mode with the optimal size of the separation of particles, to ensure high efficiency of enrichment, reduce waste from the processing process, and improve the environmental situation in the region.

5. A method for calculating the optimal value of the size of the separation of the material to be classified has been developed. Based on this, an algorithm for calculating the efficiency of beneficiation was created, which allows the obtaining of expanded information 
about the nature of changes in certain parameters with variations in the size of particle separation and screening efficiency.

6 . The use of a roller-finger screen as a combined device that separates clay coatings from pieces of rock and the separation of particles by size (including conditions of high humidity of raw materials), improves the efficiency of screening. Based on the study of the dynamics of the material particle, the determination of the forces acting on the particle, an analytical dependence is obtained, which determines the condition of excluding the mode of its clamping. It is proved that this mode does not depend on the levels of forces acting on the particle, but is determined exclusively by the values of the angles that characterize the positions of the points of contact of the particle to the finger and the lining shaft.

7. Linear regression multifactor models have been created to study the processes of enrichment and classification of raw materials, where the values of limestone content in raw materials and material moisture are used as factors, and the values of enrichment and screening efficiency indicators are used as response functions. The models allow comparison of the efficiency of screening and enrichment processes in the classification variants with and without the use of a roller-finger screen.

8. The application of Fisher's test confirmed the hypotheses about the adequacy of the developed nonlinear one-factor and linear multifactor regression models. This determines the high reliability of the results of modeling the processes of enrichment and screening of limestone.

9. With an increase of humidity of raw materials to $12 \%$ efficiency of screening of a roller-finger screen exceeds the similar indicator without its use by $30-35 \%$. The presence of a roller-finger screen is manifested in its stabilizing effect on the classification process, accompanied by an increase in the efficiency of enrichment by 10 $20 \%$. Thus, the expediency of using roll-finger screens in technological lines of enrichment of raw materials of carbonate deposits is proved.

10. A method is available for estimating the ratio of energy consumption of existing and proposed technologies for enrichment of raw materials, which allows to determine the feasibility (in terms of 
energy efficiency of the process) of introduction into the technological line of enrichment of a roll-finger screen.

11. The structure of the regression model for normalization of the indicator of specific energy consumption by the technological line of enrichment of limestone raw materials is offered. Operational control of energy efficiency by the technological line allows evaluation of the actions of operators of the process of enrichment of raw materials in the direction of reducing specific energy consumption.

\section{References}

1. Dreshpak, O. (2015). Analysis of limestone processing technology from inhomogeneous carbonate deposits, International scientific-practical conference on Problems of energy efficiency and automation in industry and agriculture. Kirovograd, Ukraine.

2. Dreshpak, O. (2016). Determination of dependences of limestone raw materials of Zapadno-Tyaginsky inhomogeneous carbonate deposit, $5^{\text {th }}$ International scientific-practical conference for young scientists and students on Actual problems of modern technologies. Ternopil, Ukraine.

3. Dreshpak, O. (2017). The features of methodology for predicting limestone dressing efficiency.International scientific-practical conference on Energy efficiency and energy saving. Dnipro, Ukraine.

4. Dreshpak, O. (2018). Mathematical model for calculating enrichment efficiency. Forum of students and young scientists "Widening our horizons". Dnipro, Ukraine.

5. Dreshpak, O. S. (2015). Determination of the degree of impoverishment of limestones of the Zapadno-Tyaginskoye deposit. Enrichment of minerals, 61(102), 56-58.

6. Dreshpak, O. S. (2018). Features of the design of the shaped disks of the roller-finger screen. Enrichment of minerals, 70(111), 6-17.

7. Dreshpak, O. S. (2018). Efficiency of beneficiation and classification of raw materials from a heterogeneous carbonate deposit. Collection of scientific works of the National Mining University, 56, 175-183.

8. Pilov, P.I., \& Dreshpak, O.S. (2019). Mathematical model for predicting limestone enrichment indicators. Journal of energy for a clean environment, 18(4), 319-333.

9. Dreshpak, N.S., Vypanasenko, S.I., \& Dreshpak, O.S. (2021). Accounting for electricity in control systems for the efficiency of its use. Mining electromechanics and automation, 103, 20-25.

10. Dreshpak, N.S., \& Vypanasenko, S.I. (2015). Informational and methodological support for energy efficiency control. Power Engineering, Control and Information Technologies in Geotechnical Systems, 1, 53-59.

11. Dreshpak, N.S., \& Vypanasenko, S.I. (2015). Algorithm for forecasting energy efficiency of steel production. Mining electromechanics and automation, 97, 108-112. 
12. Vypanasenko, S.I., \& Dreshpak, N.S. (2013). The features of energy efficiency measurement and control of production processes. Energy Efficiency Improvement of Geotechnical Systems, 1, 71-78.

13. Dreshpak, N.S., Dreshpak, O.S., \& Vypanasenko, S.I. (2021). Specific norms of energy consumption in the task of controlling the efficiency of its use. "Electrical engineering and electric power engineering", 3, 31-39.

https://doi.org/10.31713/m1108

\section{DESIGN-INDUCED OPERATIONAL CHANGES OF STRESS-STRAIN STATE IN FLAT RUBBER-CABLE TRACTIVE ELEMENT OF HOISTING AND TRANSPORTING MACHINE}

Kolosov D.L.

Dnipro University of Technology, Dnipro, Dr. Sc. (Tech.), Associate Prof., Head of Department of Structural, Theoretical and Applied Mechanics, Ukraine

Samusia V.I.

Dnipro University of Technology, Dnipro, Dr. Sc. (Tech.), Associate Prof., Head of Department of Mining Mechanics, Ukraine

\section{Bilous O.I.}

Dniprovsk State Technical University, Kamianske, Cand. Sc. (Tech.), Associate Prof., Associate Prof. of Department of Mechanical Engineering, Ukraine

\section{Tantsura H.I.}

Dniprovsk State Technical University, Kamianske, Cand. Sc. (Tech.), Associate Prof., Associate Prof. of Department of Mechanical Engineering, Ukraine

\section{Onyshchenko S.V.}

Dnipro University of Technology, Dnipro, Cand. Sc. (Tech.), Associate Prof. of Department of Structural, Theoretical and Applied Mechanics, Ukraine

Abstract.

Main indicators of a stress-strain state (SSS) of a rubber-cable belt, the rubbercable rope for a random placement pattern and the size of the part with broken cables, including partially removed cables, with cable breakages and their random 